\title{
Fronteiras agrícolas e desenvolvimento territorial - ações de governo e dinâmica do capital
}

ERNELDO SCHALLENBERGER

IARA ELISA SCHNEIDER

\section{Resumo}

O artigo desenvolve um estudo comparativo entre os processos de colonização e desenvolvimento territorial das regiões Oeste do Paraná e Alto Teles Pires - MT. Centra a sua abordagem na variável da influência do público e do privado manifesta nas políticas públicas e na dinâmica do capital - sobre a organização dos territórios das fronteiras agrícolas em questão. Toma como referência as políticas agrárias e agrícolas dos períodos históricos da era Vargas e do regime militar do pós 1964 e sua incidência sobre a construção territorial das fronteiras de colonização. Fundado na análise histórico-comparativa, evidencia a articulação dos sujeitos sociais frente as demandas do Estado e do mercado e busca aferir as implicações de tais demandas sobre a organização da sociedade e sobre o desenvolvimento local.

Palavras-chave: Migrações. Colonização. Fronteiras agrícolas. Desenvolvimento territorial.

\footnotetext{
* Dr. em História pela PUCRS; professor do CCHS e do Programa de Mestrado em Desenvolvimento Regional e Agronegócio da Universidade Estadual do Oeste do Paraná - UNIOESTE; membro do Grupo de Pesquisa Cultura, Fronteiras e Desenvolvimento Regional.

** Socióloga; mestre em Desenvolvimento Regional e Agronegócio pela Universidade Estadual do Oeste do Paraná.
} 


\section{Introdução}

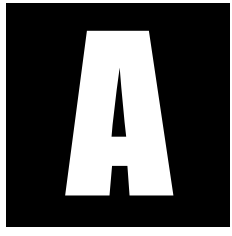

s análises centradas em torno da problemática do desenvolvimento territorial se fazem acompanhar freqüentemente de perguntas que apontam para o desenvolvimento desigual das diferentes regiões brasileiras. $\mathrm{O}$ presente artigo, fundado numa metodologia históricocomparativa, quer entender esta diferença através do estudo do processo de colonização e desenvolvimento de duas fronteiras agrícolas: Oeste do Paraná e Alto Teles Pires - do Mato Grosso. Estas fronteiras agrícolas foram integradas ao território e ao modelo de desenvolvimento nacional em contextos diferenciados, tanto sob o ponto de vista da dinâmica do capital quanto sob o das políticas de Estado. A primeira está inserida no modelo de desenvolvimento nacional inaugurado pelo governo de Getúlio Vargas após a revolução de 1930. Obedecia a meta da integração territorial e a expansão das fronteiras agrícolas em vista da expansão do mercado interno. A segunda inscreve-se no modelo desenvolvimentista associado, fundado na política agro-exportadora e implantado pelo regime militar decorrente do golpe de 1964. O estudo de caso mostrará como as regiões em epígrafe tiveram sua ocupação e desenvolvimento influenciado pelas políticas de colonização e foram, conseqüentemente, inseridas no contexto econômico e político nacional.

A trajetória do desenvolvimento, conformada ao longo da história política brasileira principalmente a partir de 1930, foi marcada por uma série de crises econômicas, abalos e rupturas institucionais. Estas crises, que assumiram caráter econômico, político e institucional, revelaram disputas de projetos políticos e de ideologias no seio da sociedade brasileira. A partir deste período, o modelo de desenvolvimento de base primárionacionalista foi sendo lentamente abandonado e substituído por outro, 
quantitativa e qualitativamente distinto, o de base industrial-exportador (IANNI, 1991).

O setor privado, fundamentalmente representado pela classe cafeicultora, até aquele momento, era incapaz de promover e organizar uma nova estrutura de desenvolvimento para o país que se pautasse na industrialização e na formação de um mercado mais eficiente. Assim, esta responsabilidade ficou a cargo do Estado, que deveria promover, executar e gerenciar uma nova política, baseada na implantação do pensamento burguês urbano. Desta forma, o Estado promoveu e regulamentou a instalação da indústria e as novas relações de trabalho que com ela surgem, como por exemplo, o assalariado urbano-industrial.

Além dessas ações, o Estado promoveu a instalação de infra-estrutura básica, começando pelos setores energético, de transportes e de uma rede de serviços. Para a objetivação das novas finalidades previstas pelos detentores do poder estatal, a aliança dos setores não tradicionais da produção agro-exportadora com a burguesia urbana motivou a efetiva participação do Estado, tanto pela via direta, através da instalação de indústrias de capital estatal, como indireta com financiamentos e incentivos à iniciativa privada. Além de incentivar a industrialização, um dos objetivos principais do período era expandir as fronteiras produtivas e incorporar novas terras e produtos ao mercado. Neste aspecto, destaca-se a importância da iniciativa privada, por meio de companhias colonizadoras particulares para a política de expansão e colonização do interior brasileiro que se intensificou a partir dos anos de 1930-1940.

Num sentido mais amplo, o conceito de colonização confunde-se com o de povoamento, isto é, o processo de ocupação e valorização de uma área, realizado por indivíduos provenientes de fora. Num sentido mais restrito, colonização é o povoamento precedido de planejamento governamental ou privado (IANNI, 1979). 
Os motivos que levam uma empresa privada a desencadear um processo de colonização de uma área são bastante diferentes do caráter oficial da iniciativa. Uma empresa particular tem seu objetivo focado no lucro. Com os loteamentos rurais, seus interesses podem estar associados às vantagens de exploração econômica predominante na área. No caso de fronteiras agrícolas em áreas de floresta, estes interesses incidem normalmente na exploração madeireira e, posteriormente, na agrícola e pecuária.

Os processos de colonização das fronteiras brasileiras se fizeram acompanhar por interesses de ordem político-militar e econômico-social. Na perspectiva político-militar, podem ser incluídos basicamente os objetivos de ocupação do território e garantia da soberania nacional nas fronteiras. Na questão socioeconômica, o deslocamento de trabalhadores e colonos favorecia a descompressão sobre o espaço agrícola e minimizava o conflito em torno da posse da terra, por um lado e, por outro, ampliava a possibilidade de geração de trabalho e renda, estimulando o aumento da produção e a ampliação do mercado.

A incorporação de novas fronteiras agrícolas ao contexto socioeconômico nacional desempenhou três funções básicas. No plano econômico, possibilitava a produção de gêneros alimentícios básicos. No plano social, representava uma orientação para os fluxos migratórios, sendo o lócus da recriação da pequena produção e, no plano político, era a válvula de escape de tensões sociais geradas no campo (SILVA, 1982).

Dessa forma, a colonização surgiu como uma opção por parte do Governo Federal, no sentido de fazer uma ampla distribuição de terras na fronteira, evitando-se, assim, uma redistribuição de terras já apropriadas no resto do país. Assim, colonização pressupõe também deslocamento, sendo que a estratégia era beneficiar diretamente os projetos de colonização privados, criando diretamente "frentes pioneiras" que canalizavam para as regiões estagnadas o excedente populacional camponês ainda 
não de todo empobrecido. Essas estratégias políticas para promover a colonização das novas fronteiras agrícolas, até então consideradas vazias do ponto de vista demográfico, influenciaram em muito o processo de desenvolvimento dos novos espaços agricultáveis.

O estudo focado nas fronteiras agrícolas do Oeste do Paraná, colonizadas no período Vargas e de Alto Teles Pires, constituídas sob o regime militar do pós 1964, está atento ao exame das relações entre o público e o privado na organização e desenvolvimento territorial dessas duas regiões, buscando sempre o entendimento da articulação dos sujeitos sociais nesse processo.

\section{A colonização das fronteiras do Oeste do Paraná e de Alto Teles Pires no Mato Grosso}

A estratégia de desenvolvimento nacional almejado pelos governos a partir de 1930, passou pela incorporação de novas terras e pelo incentivo à ocupação de áreas de fronteira, até então pouco habitadas e exploradas. Foi nesse contexto que surgiu a necessidade de colonização de novas regiões de fronteira, a exemplo do Oeste do Paraná que, por sua localização geográfica privilegiada, estava até então, à mercê da exploração estrangeira (paraguaios e argentinos), o que representava, na perspectiva geopolítica, um risco à soberania nacional.

O Oeste do Paraná foi a última região geográfica do Estado a ser colonizada e seu processo de ocupação se deu no seio do movimento político-econômico nacional denominado "Marcha para o Oeste", deflagrado no início da década de 1930, durante o governo de Getúlio Vargas. O interesse de colonização da região surgiu, portanto, da necessidade de garantir a soberania nacional e da incorporação de maiores áreas à produção agrícola, num cenário de crescimento do consumo de alimentos nos centros urbanos e da dificuldade de importação de gêneros alimentícios durante a II Guerra Mundial (GREGORY, 2002). 
A "Marcha para o Oeste" proposta pelo governo Vargas, era formada por um conjunto de ações governamentais bastante variadas que iam desde a implantação de colônias agrícolas, passando pela abertura de novas estradas, até obras de saneamento rural e de construção de hospitais. Esta política nacional expansionista buscava a integração nacional e, concomitantemente, a organização dos territórios, garantindo dessa forma, além da segurança e da efetiva posse, a exploração produtiva de imensas regiões fronteiriças praticamente inabitadas (LOPES, 2002).

Diante do interesse de efetivar a colonização e a inserção produtiva da região Oeste do Paraná, o Estado uniu forças com as companhias colonizadoras particulares e definiu alguns critérios para que o empreendimento tivesse sucesso. Dentre esses critérios, a estrutura fundiária teve significado especial, tendo em vista que o minifúndio garantiria uma ocupação mais densa da área, com redes de relações familiares e sociais sólidas e, ao mesmo tempo, em que estimularia o incremento populacional, promoveria o abastecimento do mercado através da produção diversificada de excedentes.

O desenvolvimento dessa nova economia em formação esteve condicionado, antes de tudo, à constituição e ampliação de um mercado interno que teria que ser dinamizado numa ponta pelo aumento e diversificação da produção e, na outra, pela ampliação do consumo interno. Dentre os fatores que pressionaram estas mudanças pode-se citar o crescimento da população e a elevação do seu padrão de vida, de suas exigências e necessidades. Aos poucos, a produção interna, tanto agrícola como industrial, pôde ir fazendo frente às demandas de consumo. A indústria nacional foi progressivamente substituindo, com seus produtos, a importação anterior de quase tudo o que diz respeito a artigos de consumo imediato, isto é, as manufaturas leves (IANNI, 1991).

Este contexto refere-se ao que Getúlio Vargas chamava de "arrumar a casa", ou seja, criar as bases de sustentação da economia, pautada 
numa agricultura diversificada e na estruturação da indústria, principalmente de gêneros alimentícios.

No padrão de desenvolvimento inaugurado com a mudança do eixo dinâmico da economia brasileira a partir de 1930 e com a conseqüente ruptura da hegemonia que possuíam os exportadores, particularmente os de café, o Estado passou a exercer liderança ativa no modelo de desenvolvimento econômico, fundado no projeto de consolidação da indústria nacional. No Brasil, o Estado sempre cumpriu papel de destaque no manejo dos instrumentos da política econômica, entretanto, a partir de 1930, o exercício da liderança ativa tornou-se qualitativamente distinta de períodos anteriores. Tratava-se de promover as modernizações social, econômica e administrativa do país (VIEIRA, 2003).

O grupo que comandou o Estado a partir de 1930, sob a liderança de Getúlio Vargas, tinha a percepção de um modelo de desenvolvimento fundado na concepção de um capitalismo nacionalista. Assim, a nação poderia libertar-se das demais, através do desenvolvimento e do fortalecimento do seu próprio parque industrial e da sua agricultura, formando seus técnicos e regularizando as relações entre o capital e o trabalho.

Destacaram-se, porém, na história econômica brasileira do pós 1930, duas estratégias diferenciadas para promover o desenvolvimento:

Uma dessas tendências, que pode ser denominada estratégia de desenvolvimento nacionalista, predominou nos anos 1930-1945, 1951-54 e 1961-64. Ela tinha como pressuposto implícito, o projeto de um capitalismo nacional, como uma única alternativa para o progresso econômico e social. Nota-se que o capitalismo nacional deveria implicar na crescente nacionalização dos centros de decisão sobre assuntos econômicos e continha o pressuposto de uma hegemonia possível, principalmente nas relações com os países da América Latina e da África. A outra pode ser chamada estratégia de desenvolvimento associado, predominou nos anos de 1946-50, 1955-60 e de 1964 em diante. Ela continha, 
como pressuposto implícito e explícito, o projeto de um capitalismo associado como única alternativa para o progresso econômico e social (IANNI, 1986, p. 307-308).

A principal diretriz que orientou o mandato de Getúlio Vargas esteve pautada na doutrina nacionalista, orientada fundamentalmente para o fortalecimento da economia nacional, com o intuito de libertar o país de influências externas, incompatíveis com seus interesses.

Como forma de identificar diferenças entre as políticas que favoreceram a colonização a partir do padrão de desenvolvimento inaugurado em 1930, é possível distinguir duas fases. A primeira, que vai de 1930 até 1964, quando as experiências de colonização foram intensificadas. Neste período, a "Marcha para o Oeste" e as Colônias Agrícolas Nacionais ${ }^{1}$ conseguiram alcançar alguma repercussão no país. As políticas formuladas, ainda que precárias, buscavam possibilitar a integração do território nacional pela inclusão das fronteiras ocas ${ }^{2}$ ao mercado interno, que paulatinamente se ia formando. A dificuldade para que o projeto pudesse completar-se residia, fundamentalmente, na incipiente estrutura econômica. A ausência de uma maior e melhor articulação entre as estruturas financeira, de investimentos e de distribuição, impossibilitou a disseminação, pelo território nacional, de experiências deste quilate (LENHARO, 1986).

A segunda fase iniciou-se em 1964 e se estendeu até fins dos 80, quando este padrão de desenvolvimento parece ter sofrido forte inflexão, com o fim da ditadura militar. Este recorte temporal evidencia o golpe militar como um dos elementos centrais e que conferiram marca própria aos processos de colonização que, a partir daí, ganharam relevo e destaque no cenário nacional. Neste sentido, as experiências de colonização têm

1 Lotes de terras em áreas de fronteira, distribuídas pelo governo para promover a ocupação e garantir, principalmente, a soberania e segurança nacional.

2 Fronteiras ocas eram denominados os espaços vazios nas áreas de fronteira. 
no Estado um forte aliado. Todo o aparato institucional e as políticas públicas implementadas desde então foram quantitativa e qualitativamente distintas dos projetos de colonização ocorridos entre 1930 e 1964.

De um modo geral, o que distingue as políticas econômicas e de planejamento do segundo governo de Getulio Vargas (1951-54) e de Juscelino Kubitschek (1956-61) é a transição de uma política destinada a criar um sistema capitalista nacional para uma política orientada para o desenvolvimento econômico dependente, ou associada aos mercados estrangeiros.

A política do capitalismo nacional foi rompida pela política da estratégia de desenvolvimento associado, a partir de 1955, quando o presidente Juscelino Kubitschek - JK - promoveu o discurso de grandes empreendimentos para o Brasil, querendo fazer o país crescer em 5 anos o que ele não tinha crescido em 50. Esta fantástica fórmula, para ser concretizada, teria que romper necessariamente com a política nacionalista e abrir as fronteiras para a livre entrada, circulação e exploração do capital estrangeiro. É uma postura que aceita e promove o capital estrangeiro para socorrer a burguesia nacional, além do que visava livrar o Estado da execução de projetos de produção e implantação de infra-estruturas necessárias para o crescimento econômico do país.

O governo JK criou uma série de programas destinados ao desenvolvimento, dentre eles o Programa de Metas que visava, de um modo geral, transformar a estrutura econômica do país, pela criação da indústria de base e a reformulação das condições reais de interdependência com o capitalismo mundial. Dentre os objetivos do Programa, destacavam-se os seguintes: abolir os pontos de estrangulamento da economia, por meio de investimentos em infra-estrutura a cargo do Estado; expandir a indústria de base como a automobilística e ainda, estimular a poupança nacional e a modernização geral do sistema produtivo. Além disso, um dos alvos 
centrais do programa era atrair o interesse de empresários estrangeiros, com seu capital e sua tecnologia (IANNI, 1991).

A base mais forte de compreensão da política que orientava o planejamento do Estado voltado para o capital estrangeiro é a que demonstrava que o Brasil poderia superar as estruturas arcaicas em tempo mínimo, pela incorporação de tecnologias já inventadas nos países desenvolvidos e pela instalação, em território brasileiro, de capacidades administrativas, de gerenciamento, de exploração e de transformação da matéria-prima, de articulação de políticas para o setor energético e de transportes (ZART, 1998).

A partir desta nova perspectiva política e econômica, a História teve outros contornos. Já com a instauração do governo militar em 1964, que sucedeu o de Juscelino Kubitschek, a estrutura econômica erigida com o Plano de Metas alcançou grande consistência e integração. Desde então, as estruturas de financiamento, de investimentos e de distribuição amadureceram seus instrumentos, tornando-se, a um só tempo, mais ágeis e mais consistentes. Em poucos anos, a colonização dirigida pôde ser impulsionada e o que se viu foi a proliferação das experiências de colonização por toda a área da Amazônia Legal, com absoluto destaque para o Estado do Mato Grosso no que se refere à colonização particular (VIEIRA, 2003).

Na verdade, as políticas de planejamento do governo militar, são uma extensão do que já havia sido iniciado no governo JK, em meados de 1950. Dentre os principais alvos destacaram-se: o incentivo à exportação de produtos agrícolas, minerais e manufaturados; o estímulo, sob o comando do Estado, do mercado de capitais; a criação de condições e estímulos novos à entrada de capital e tecnologia estrangeira; a modernização das estruturas urbanas; a criação de novos meios de ocupação e dinamização da economia da Amazônia. Neste último ponto, pode-se destacar a abertura e execução de obras rodoviárias, com o intuito de ocupar e tornar produtivas 
as terras da região Amazônica, estimulando para isso correntes migratórias vindas de todos os cantos do país (IANNI, 1991).

A colonização que se difundiu após 1964 apresentava, no entanto, um duplo caráter, ausente no período anterior: pretendia, por um lado, mediar a valorização de capitais privados das empresas de colonização com os interesses geo-estratégicos e de segurança interna do Estado e, por outro, constituir uma alternativa viável à resolução da questão agrária.

O conceito político-militar da 'ordem e progresso', presente após o golpe de 1964 traz no seu significado a concepção da filosofia política elaborada pela Escola Superior de Guerra. ${ }^{3}$ Esta filosofia pregava, dentre outras coisas, os princípios da seguridade e da integridade do território nacional, a defesa da propriedade, da liberdade e da democracia. Em geral, neste período continuou prevalecendo o pensamento empíricopositivista que vinha orientando os governos anteriores e que tinha como ideal o desenvolvimento e ocupação de regiões de fronteira (ZART, 1998).

A ocupação dessas áreas de fronteira passava pela estratégia geopolítica do Estado, que objetivava, segundo os princípios da Escola Superior de Guerra, ocupar e desenvolver as regiões denominadas de "espaços vazios" e "fronteira oca". A questão central era a de promover a efetiva ocupação de regiões geográficas, levando a elas a civilização para promover a integração territorial em base a três elementos básicos, constituintes das relações capitalistas de produção: o homem, o capital e o trabalho (IANNI, 1986).

Da doutrina de segurança nacional e das mensagens presidenciais derivava a ordem de transformar as fronteiras vazias, primeiramente num espaço político, através da ocupação, e, depois, num espaço econômico. Esta ideologia fica evidente tanto nos projetos de colonização implementados antes de 1964 como nos implantados nos anos posteriores. A multi-

3 A Escola Superior de Guerra foi criada em 20 de agosto de 1949, com a finalidade de elaborar uma doutrina de segurança nacional. 
plicação dos projetos de colonização na área da Amazônia Legal durante o regime militar resultou das opções contidas nas orientações políticas e econômicas do Estado brasileiro. Neste contexto, a vertente reformista do Estatuto da Terra - favorável à reforma agrária - foi rapidamente suplantada pela de caráter modernizador. Com isto, a política agrícola de estímulo à pequena propriedade, estruturada para o abastecimento do mercado interno deu lugar à empresa rural, associada aos interesses do mercado agro-exportador e de commodities.

É nessa época, que ocorre a efetiva colonização do Estado do Mato Grosso, em especial na sua fronteira Norte, pertencente à região da Amazônia Legal, da qual faz parte a microrregião de Alto Teles Pires. Alicerçados na ideologia da segurança nacional e da integração territorial, foram criados, no regime militar, projetos federais como o Programa Integrado de Desenvolvimento do Noroeste do Brasil - POLONOROESTE e o Programa de Integração Nacional - PIN. Estes projetos tinham, sob o comando do Instituto Nacional de Colonização e Reforma Agrária - INCRA, os objetivos de promover o incremento populacional e a inserção econômica da região no contexto nacional (CUNHA, et al, 2004).

O modelo fundiário implementado em Alto Teles Pires era, inicialmente, parecido com o da região Oeste do Paraná, ou seja, organizado em base aos minifúndios. O governo fazia concessões de terras devolutas a pequenos proprietários rurais vindos de todas as partes do país, sobretudo aos da região sul.

Este modelo, entretanto, fracassou, principalmente devido aos grandes investimentos que deveriam ser feitos para que a terra se tornasse produtiva e pela distância da região dos grandes centros consumidores, o que encarecia em muito o cultivo e o escoamento da produção. Assim, em meados da década de 1970, o Governo passou a estimular a implantação de projetos agropecuários e agro minerais na região, através da con- 
cessão de incentivos fiscais e creditícios a grandes empresas nacionais e multinacionais. A colonização gerenciada por empresas privadas ganhou impulso, principalmente ao longo da rodovia BR 163 (Cuiabá-Santarém), fazendo surgir cidades como Sorriso e Lucas do Rio Verde, pertencentes à microrregião de Alto Teles Pires.

Na colonização do Estado do Mato Grosso, a mudança de postura do Governo Federal tornou-se visível. Até o início da década de 1970, a prioridade era a colonização com ênfase social, que optava por camponeses mais pobres, visando a implantação de pequenas propriedades rurais. A partir de 1975, o governo adotou uma colonização fundamentada no espírito comercial, marcada pela venda de grandes extensões de terra a empresas colonizadoras. Com a marcante interferência das esferas política e econômica, passou a predominar na região a empresa agropecuária voltada ao mercado exportador (BECKER, 1997).

O governo considera impraticável a colonização baseada em pequenos e médios proprietários frente à escala dos investimentos e de organização empresarial considerada necessária à ocupação rápida de uma área extensa como a Amazônia. É o próprio governo, porém que avaliza e credita subsídios aos empresários, através do mecanismo de incentivos fiscais (BECKER, 1997, p. 26).

Todo esse processo provocou grandes impactos na ocupação e no desenvolvimento econômico, não só do Estado de Mato Grosso, mas de toda a região Centro-Oeste e da Amazônia. A política de isenção fiscal e a dedução do imposto de renda adotada nessa época, contribuíram para aumentar, cada vez mais, a concentração de terras no Brasil.

Ao que tudo indica, pelas características das propriedades atuais, embora nas fases iniciais da colonização tenha havido oportunidades para que pequenos agricultores se estabelecessem no Mato Grosso e em toda região, o que ocorreu foi a incorporação dessas pequenas propriedades 
pelas maiores. O resultado deste processo é uma maior concentração fundiária em torno das grandes fazendas de criação de gado, das atividades extrativas (madeira e minérios) e das propriedades monoculturas, ou, ainda, de grandes áreas ociosas que passaram a servir como "reserva de valor", em vista do mercado futuro (BECKER, 1997).

O contexto histórico em que ocorreu a organização do território mato-grossense transformou essa área numa grande fronteira agrícola, em constante expansão. E é perceptível uma diferença entre a antiga colonização da área e o modelo atual de ocupação. No passado, o povoamento e o investimento se vinculavam à atividade agrícola ou mineradora e geravam crescimento da população e da produção. Ao final do século XX, a fronteira começou a apresentar novas feições, uma vez que se ajustou a um novo patamar de integração nacional, inserida num mercado globalizado e sob comando de uma nova dimensão dos capitais envolvidos.

A passagem do padrão de acumulação de base primário-nacionalista a outro de base industrial-exportador trouxe consigo uma multiplicação de temas e polêmicas debatidos no interior da sociedade brasileira. Dentre eles, destacam-se os da questão agrária, notadamente em virtude da passagem do padrão do minifúndio de exploração familiar para o latifúndio empresarial e a transferência do eixo da acumulação de capital do espaço rural para o urbano.

A agricultura, especialmente no que diz respeito à produção de commodities, passou a sustentar a produção urbana, respondendo pela geração de divisas necessárias à importação de bens de produção não produzidos no país. Além disso, a agricultura passou a responder pela produção de alimentos para o mercado interno.

Não por acaso, o planejamento econômico assumiu, a partir destes anos, importância ímpar para a superação do relativo "atraso" em que se encontrava o país. As transformações estruturais pelas quais vinha passando 
a economia brasileira naqueles anos, atingiram seu clímax entre as décadas de 1950 e 1960. Os intensos debates e as acaloradas polêmicas do período davam o tom do "estado de espírito" das forças sociais que se apresentavam na cena política, buscando articular interesses e propostas em torno da temática do desenvolvimento econômico. O Estado passou a operar mecanismos de perdas e ganhos entre as classes proprietárias, a amparar as atividades industriais, induzir as agrícolas a cumprirem papéis novos e manejar instrumentos de política econômica em prol da industrialização. Com isto pretendia criar e recriar uma estrutura própria aos requisitos necessários à realização de um certo padrão de acumulação (VIEIRA, 2003).

Se a modernização acoplava o agro à indústria, a colonização era vista como alternativa aos conflitos agrários do país, buscando minimizálos através da migração de trabalhadores, muitas vezes transformados em colonos, sobretudo os do Nordeste e do Sul do país. No caso da região de Alto Teles Pires, no Estado do Mato Grosso, palco privilegiado das experiências de colonização dirigida de caráter privado, os projetos existentes caracterizaram-se como "fortalezas do capital privado" (BECKER, 1997).

Para dar sustentação a este padrão, uma medida adotada foi a colonização dirigida, que passou a ser da responsabilidade do Estado, e que pretendia, de modo geral, recriar novos espaços de produção para a economia nacional, bem como garantir a segurança nacional com a ocupação de espaços demograficamente "vazios". Em outras palavras, os fatos que ocorreram neste período, trouxeram expressivos desdobramentos, quer de natureza social, quer política ou econômica, no que se refere a estímulos recebidos para a realização de empreendimentos de colonização que ganharam destaque, a partir da década de 1970.

A ocupação dos "espaços vazios" por questão de segurança nacional já era uma prática recorrente do governo Vargas. Com a instauração do regime militar, ocorreu uma mudança substancial em relação à base eco- 
nômica e agrária do país, fundada na especialização da produção agrícola para a exportação e na grande propriedade monocultora. O crescente volume de capital privado na agricultura esteve, cada vez mais, associado aos interesses dos grupos controladores do mercado mundial de insumos e grãos. Diante disso, os minifúndios da região Oeste do Paraná, organizados para atender as demandas diversificadas do mercado interno, tornaram-se inviáveis, o que fez com que muitos produtores rurais fossem levados a buscar espaços produtivos mais amplos, encontrados nos latifúndios da região de colonização de Alto Teles Pires, no Mato Grosso.

A política de colonização no Brasil, adotada pelo regime militar do pós 1964, se constituiu na alternativa escolhida pelas classes dominantes para evitar, simultaneamente, a necessária reforma estrutural do campo e suprir seus projetos na fronteira agrícola. Dessa forma, a abertura das novas frentes de ocupação na Amazônia trouxe consigo um caráter contraditório da formação da estrutura fundiária brasileira no interior da lógica do desenvolvimento capitalista: o processo que levou os grandes capitalistas a investirem na fronteira se fez acompanhar da necessidade de abertura dessa fronteira aos camponeses e demais trabalhadores do campo, que se transformaram na força de trabalho para a execução dos projetos capitalistas.

O uso do território, que historicamente se dá de forma seletiva e desigual, revela-nos a face geográfica da desigualdade, dada por organizações territoriais e pelas normativas políticas. Assim, é possível afirmar que nas regiões estudadas, os fatores exógenos, representados pelas políticas econômicas e de desenvolvimento nacional, atuaram diretamente sobre o crescimento. A execução dessas políticas teve curso por diversas vias, tais como: concessão de crédito rural, incentivo à inovação tecnológica, compra de insumos e maquinários subsidiados, garantia de preços mínimos, entre outras.

Obviamente que este desenvolvimento não se fez sem mazelas sociais, como o êxodo rural, o inchamento das cidades e a depredação do 
meio ambiente. Há de se considerar, porém, que as medidas adotadas trouxeram inúmeros benefícios e que tinham caráter de urgência na época, em se considerando, sob a ótica dos interesses hegemônicos, a garantia da soberania nacional, através da ocupação das fronteiras e a inserção de novas áreas à economia nacional.

Atualmente, o agronegócio dá a tônica do desenvolvimento dessas regiões. A pecuária e a agricultura moderna de exportação impulsionam o comércio e a economia regional, fornecendo as bases para implantação de indústrias. Este processo provoca um expressivo movimento de capitais, serviços e pessoas, que se reflete sobre a acelerada urbanização que acontece nessas áreas.

\section{Considerações finais}

A análise comparada das incidências das políticas de colonização do Estado brasileiro do antes e pós-regime militar permite aproximar experiências que, reduzidas ao foco de duas fronteiras agrícolas - Oeste do Paraná e de Alto Teles Pires no Mato Grosso - possibilita o entendimento da relação existente entre a dinâmica do capital e as ações de governo no que diz respeito à organização territorial e ao modelo de desenvolvimento econômico.

Na colonização da região Sul do país, a partir da década de 1940, prevaleceram os minifúndios, destinados a produzir para o abastecimento do mercado interno. Apareceu implícito, porém, nesta configuração, o ideal do governo getulista de criar as bases para a industrialização nacional, sem, contudo, estar dependente das imposições externas. Para isso, era necessário fortalecer a economia interna e criar um mercado de trabalho com leis e diretrizes que amparassem os trabalhadores, de modo que estes se sujeitassem às exigências do trabalho industrial. 
No período que antecede à abertura da fronteira agrícola no Estado do Mato Grosso, as bases da industrialização já estavam lançadas e surgiram, a partir daí, novas estratégias de desenvolvimento, arquitetadas pelo governo militar. Foi um período de expansão do capitalismo no campo, onde as políticas de planejamento privilegiaram a instalação de empresas multinacionais de grande porte na região.

As políticas de colonização projetadas sobre as regiões em epígrafe estiveram intimamente ligadas às estratégias de integração do território nacional e, ao mesmo tempo, atenderam demandas específicas, quer do modelo de desenvolvimento nacional, quer do macro-mercado capitalista internacional. Assim, com o período Vargas, o Estado passou a exercer forte influência sobre a organização do território e fomentava o aumento e a diversificação da produção pela integração de novos espaços produtivos e a sua inserção no circuito de mercado nacional. Foi organizada, para isto, uma colonização embasada em pequenas propriedades rurais, com a diversificação da agricultura para o abastecimento do mercado brasileiro.

As políticas formuladas a partir do governo de Juscelino Kubitschek e consolidadas durante o regime militar indicavam para a necessidade de abrir o mercado nacional para o capital externo e voltar a produção agrícola para a exportação. Novas fronteiras agrícolas foram integradas ao espaço econômico nacional. Nesse período, teve curso a colonização de quase todo o Estado do Mato Grosso, especialmente da microrregião de Alto Teles Pires, que passou a se destacar pela produção de grãos e por uma agricultura altamente mecanizada.

O processo de modernização do território, intensificado com o regime militar, garantiu a definitiva transformação do meio geográfico em meio técnico, científico e informacional, atendendo às exigências de um mundo cada vez mais atingido pela globalização. Urbanização, industrialização e modernização agrícola são marcas deste período. A agricultura 
tornou-se uma atividade científica, fortemente dependente da informação e da pesquisa. Esta agricultura modernizada alterou as relações cidade-campo e exigiu a implantação de sistemas de engenharia complexos que garantissem a produção e, sobretudo, a circulação, uma vez que o mercado precedia a produção propriamente dita.

O Estado participou de forma generosa nesse processo, garantindo a implantação de redes de circulação e comunicação. Esta agricultura vinculada diretamente ao mercado externo teve seus preços e sua produção definidos por ele, o que levou a economia brasileira a uma incômoda posição de subordinação, determinada pelo modelo agrário-exportador.

A renúncia ao modelo de desenvolvimento nacional e o propósito de um desenvolvimento associado desconstituíram o Estado do controle dos processos econômicos, entregando-os às forças do mercado. As flutuantes "forças de mercado", que são extraterritoriais na expressão de Bauman (2003, p.93), desconcertaram a organização territorial produzida pelas frentes de colonização, dando lugar aos migrantes econômicos que passaram a se valer dos sujeitos da colonização como consumidores/fornecedores ou como força de trabalho. As estruturas produtivas, voltadas para o mercado agro-exportador, conferiram às unidades produtivas um caráter empresarial, do que resultou um processo de concentração das propriedades e o deslocamento de grandes contingentes para novas fronteiras de trabalho e renda. O desarranjo territorial e o desengajamento social decorrentes deste processo promoveram fissuras na ordem e na representação sociocultural dos sujeitos da construção dos espaços sociais da colonização das novas fronteiras agrícolas. 


\section{Agricultural frontiers and territorial development - govern- ment actions and capital dynamics}

\section{Abstract}

This paper develops a comparative study of the processes of colonization and territorial development in the western part of Paraná state and Alto Teles Pires, in the state of Mato Grosso. The focus of its approach is the variable that is the influence of public and private interests - manifested in the form of public policies and capital dynamics - on the organization of the agricultural frontiers of the territories in question. The authors consider the agrarian and agricultural policies of the historical period known as the Vargas years and the post-1964 military regime, and its impact on the territorial construction of colonization frontiers. Based on an historical and comparative analysis, the article emphasizes the articulation of social subjects to meet the demands of the State and the market, and intends to assess the implications of such demands on the organization of society and on local development.

Keywords: Migration. Colonization. Agricultural frontiers. Territorial development.

\section{Referências}

BAUMAN, Zygmunt. Comunidade: a busca por segurança no mundo atual. Rio de Janeiro: Jorge Zahar, 2003.

BECKER, Berta Koiffmann. Amazônia. 5ed. São Paulo: Ática, 1997.

CUNHA, José Marcos Pinto da et al. Diagnósticos Regionais do Estado do Mato Grosso. Campinas: Núcleo de Estudos de População/Unicamp, 2004.

GREGORY, Valdir. Os eurobrasileiros e o espaço colonial: migrações no Oeste do Paraná. Cascavel: Edunioeste, 2002.

IANNI, Octavio. Colonização e Contra-Reforma Agrária na Amazônia. Petrópolis: Vozes, 1979.

. Ditadura e Agricultura: O desenvolvimento do capitalismo na Amazônia: 1964-1978. Rio de Janeiro: Civilização Brasileira, 1986.

. Estado e Planejamento Econômico no Brasil. 5 ${ }^{\underline{a}}$ ed. Rio de Janeiro:

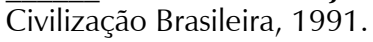


LENHARO, Alcir. Colonização e Trabalho no Brasil: Amazônia, Nordeste e Centro-Oeste. Campinas: EdUnicamp, 1986.

LOPES, Sérgio. O Território do Iguaçu no contexto da "Marcha para Oeste". Cascavel: Edunioeste, 2002.

SILVA, José Graziano da. A modernização dolorosa. Rio de Janeiro: Zahar Editores, 1982.

VIEIRA, Paulo Alberto dos Santos. Ordem e Progresso: Colonização e Desenvolvimento em Mato Grosso, o caso de Sinop. Minas Gerais. Dissertação de Mestrado. Universidade Federal de Uberlândia - MG, 2003.

ZART, Laudemir Luis. Desencanto na nova terra: assentamento no município de Lucas do Rio Verde-MT na década de 80. Santa Catarina. Dissertação de Mestrado. Universidade Federal de Santa Catarina - UFSC, 1998.

Recebido: 17/06/2008

Aceite final: 12/11/2008 